\title{
Analysis of mtDNA haplotypes of kelp bass tests for sibling-dominated recruitment near marine protected areas of the California Channel Islands
}

\author{
Christina W. Luzier, Raymond R. Wilson Jr.* \\ Department of Biological Sciences, California State University, Long Beach, 1250 Bellflower Boulevard, Long Beach, \\ California 90840, USA
}

\begin{abstract}
Marine protected areas (MPAs) have been heralded as the next important fisheries management tool. Predicted benefits include increased fish biomass, increased species diversity, and enhanced recruitment to the MPA itself, as well as to proximal areas. Whereas MPAs have in fact been shown to increase biomass and species diversity, evidence of enhanced recruitment has yet to be seen. If MPAs are significantly enhancing recruitment, one would expect to see the recruitment dominated by groups of siblings arising from highly productive females predicted to eventually reside in MPAs due to the protection afforded them. If occurring, such sibling-dominated recruitment could be identified by significantly fewer mtDNA haplotypes and significantly fewer singleton haplotypes in population samples of recruiting juveniles compared to adult populations. We investigated a new approach for potentially determining whether MPAs might be significantly enhancing recruitment to proximal areas of Santa Cruz and the Santa Catalina islands in the California Channel Islands, by seeking evidence of sibling-dominated juvenile recruitment in mitochondrial DNA haplotype data of the kelp bass Paralabrax clathratus. Our analyses found largely genetically mixed recruitment from the plankton, suggesting that recruitment to the sampled areas was not being measurably enhanced from point sources such as the nearby MPAs.
\end{abstract}

KEY WORDS: mtDNA singleton fraction $\cdot$ Natal homing $\cdot$ Effective population size Resale or republication not permitted without written consent of the publisher

\section{INTRODUCTION}

Marine protected areas (MPAs) have been heralded as the next important fisheries management tool, with expected benefits of increased fish biomass, increased species diversity, and enhanced recruitment to the MPA, as well as to its proximal areas (Conover et al. 2000). MPAs comprise generally of 2 types: strictly notake areas where no fishing is allowed, and marine sanctuaries where traditional fishing activities (excluding the harvest of endangered populations) are normally allowed. There are 70 MPAs in the waters off California, each providing varying amounts of protection for species inside their boundaries. Fishing is either restricted or completely prohibited for some or all species. There are many MPAs throughout the world, including the United States, Australia, Canada,
Europe, New Zealand, South Africa and the Caribbean Sea; where in each case the level of protection varies and is dependent upon the status of the species within the MPA.

MPAs are reported to increase biomass and species diversity within their borders (e.g. Chiappone \& Sullivan Sealey 2000, Roberts et al. 2001), and could prove effective in enhancing adult fish stocks through spillover. However, determining whether MPAs significantly enhance total population recruitment is difficult, as recruits are not easily tracked from natal to settlement sites, a trek of more than 1 mo for many fishes (e.g. Victor 1987, Waples 1987). Nevertheless, the potential contribution of juveniles recruiting from pelagic larvae must be included when assessing the overall effectiveness of MPAs, because knowledge of recruitment patterns, and specifically whether or not a 
population or stock mostly replenishes itself or receives substantial recruitment from elsewhere, could help determine the effectiveness of MPAs.

An important recreational fish of southern California that might benefit from MPAs is the kelp bass Paralabrax clathratus. Although it is illegal in California to sell kelp bass, a single recreational fishing vessel can still take as many as 5000 fish from 1 reef in a single year (Love 1996). The species occurs from the Columbia River in Washington, USA, to southern Baja California, Mexico. It reaches $72 \mathrm{~cm}$ in total length, lives to about $33 \mathrm{yr}$, and is typically mature after $3 \mathrm{yr}$ of age. It is principally found between 3 and $25 \mathrm{~m}$ depth around structure such as reefs, rocks, oil platforms and, especially, giant kelp (Love 1996). Breeding occurs between April and November; the eggs hatch 1 to $2 \mathrm{~d}$ post-fertilization, and the larvae are planktonic for about 28 to $30 \mathrm{~d}$ before settlement in late summer (Cordes \& Allen 1997, Findlay \& Allen 2002). Adult kelp bass are apparently non-migratory (Young 1963, Love 1996, Lowe et al. 2003).

As allozyme data have suggested (Waples 1987), a planktonic phase lasting ca. 28 d should produce a panmixis of kelp bass throughout the Southern California Bight, even without adult migration. If so, traditional genetic approaches could prove problematic for detecting progeny recruiting near their sites of origin, such as an MPA. Whereas promising methods involving the chemical marking of otoliths have been developed to identify juvenile natal homing and local retention of juvenile fish recruiting to coral reefs (Jones et al. 1999, Swearer et al. 1999), their applicability to similar studies of fishes in temperate habitats has not been demonstrated. Consequently, we investigate the possibility of modifying traditional genetic methods to provide a genetic 'tagging' approach to examine patterns of juvenile recruitment near 2 MPAs in California.

Wilson et al. (1997) and Wilson \& Donaldson (1998) elaborated the potential use of mitochondrial DNA (mtDNA) for genetic tracking and tagging of fishes. As mtDNA is maternally (clonally) inherited, all progeny of an individual female should possess the same mtDNA haplotype regardless of paternal contribution; thus, maternal siblings would share the maternal haplotype. Excessive propagation and release of progeny from few females, such as might occur for example through artificial stock enhancement (Wilson et al. 1997), should produce disproportionately high occurrences of the mtDNA haplotypes of those few females (Wilson \& Donaldson 1998), and field sampling of juveniles near the time and place of a release should reveal many examples of their mtDNAs. The strength of the haplotype 'signal' would diminish through time as the fish dispersed and experienced natural mortality, but should some event return large numbers of cohort sur- vivors to their release site, field sampling should again reveal high relative occurrences of those maternal haplotypes.

For an MPA to be self-sustaining or to supply significantly enhanced recruitment (i.e. much above background levels) to proximal areas, female residents would have to produce excessive numbers of progeny that must in some manner return and recruit to or near the natal site. Indeed, the high density of fishes within an MPA, coupled with the high fecundity expected from their large size and longevity (e.g. Roberts et al. 2001), are expected to result in disproportionately high numbers of progeny per number of female contributors and area occupied than smaller and more widely scattered females outside the MPA. Local enhancement from juvenile natal homing (if it occurs) could (as in artificial stock enhancement) result in disproportionately high numbers of the mtDNAs of the females that spawned them, possibly giving rise to recruits dominated by sibling groups of the contributing females. Finding initial evidence of such sibling-dominated recruitment would not immediately depend on precise haplotype recognition of specific females of an MPA. It would be sufficient initially to ascertain the mtDNA singleton haplotype fraction of the recruiting juveniles.

A 'singleton' mtDNA haplotype is defined as a haplotype seen only once in a sample, i.e. an unshared haplotype. Least-squares regression analysis of genetic data of fish populations from a few studies that have used mtDNA control-region sequences of adults to define haplotypes (e.g. Bowen \& Grant 1997, Brown et al. 1993, Shields \& Gust 1995, Stepien 1995, 1999, Stepien \& Faber 1998, Stepien et al. 2000, Dawson et al. 2002) suggests that the rate at which singletons are found with finite population sampling is proportional to the rate at which new haplotypes are discovered, thus allowing comparison among studies (Fig. 1). The regression slope is the mean number of singletons expected for the total number of distinct haplotypes found; thus, this 'composite' adult regression might prove useful for studying juvenile recruitment.

Progeny of highly productive, albeit perhaps few, spawning females of an MPA recruiting en masse should not display the high singleton fraction characteristic of genetically well-mixed adult populations (Fig. 1). Rather, there should be many maternal siblings among them, significantly lowering the numbers of singleton haplotypes that would be present in a sample of recruiting juveniles. However, finding only a significantly lowered singleton count near an MPA could not identify it as the recruitment source, because a low count might result from groups of true maternal siblings or, especially, of nominal siblings recruiting to any southern California location. However, if juvenile natal homing or another form of local retention is fre- 


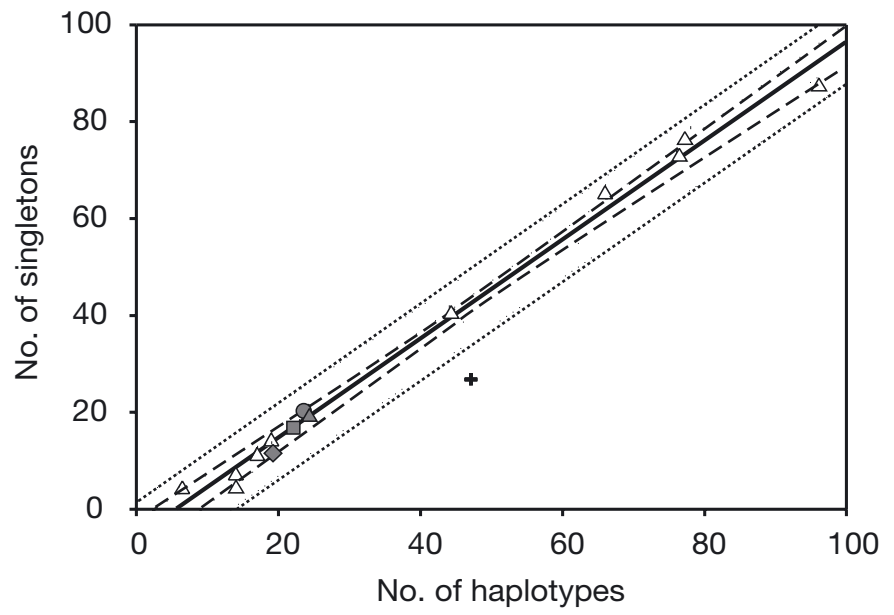

Fig. 1. Least-squares linear regression of total numbers of singletons versus distinct haplotypes taken from population genetic studies of 10 species of adult marine and freshwater fishes that analyzed control-region sequences of mtDNA. Equation of line (adult composite regression) is: $Y=1.02$ $( \pm 0.0795 \%$ CI $) X-5.9 ; \mathrm{R}^{2}=99.2 \% ; \mathrm{p}<0.001$. The $95 \%$ prediction interval for new $(X)$ observations is approximately $Y \pm$ 7.65. $(\Delta)$ Regression equation data taken from (left to right along regression line) Stepien (1999), Stepien \& Faber (1998), Stepien et al. (2000), Shields \& Gust (1995), Brown et al. (1993), Stepien et al. (2000), Dawson et al. (2002), Stepien (1995), Bowen \& Grant (1997), Stepien (1999). Filled symbols are for Paralabrax clathratus; they are plotted but not included in regression equation. ( $\diamond)$ Hazards Bay juveniles; $(\Delta)$ Pelican Bay juveniles; ( $\square)$ Ripper's Reef juveniles; (O) Catalina adults; (+) pooled juvenile sample

quently occurring among kelp bass, one would expect evidence of it near MPAs if they are indeed highly productive.

Our study therefore sought evidence of siblingdominated recruitment both near an MPA, and some distance away, by analyzing of mtDNA control-region sequences of kelp bass juveniles recruiting near 2 small and widely separated MPAs off southern California. A significant reduction in singleton counts among recruiting Paralabrax clathratus juveniles relative to the composite adult fraction (Fig. 1) would provide initial evidence of locally-derived (i.e. enhanced) recruitment, possibly with some contribution from the MPAs. No reduction in singleton counts would suggest geneticallymixed recruitment, possibly from several sources, and consequently no significant local enhancement.

\section{MATERIALS AND METHODS}

Specimen collection. We obtained Paralabrax clathratus juveniles that had recruited to Standard Monitoring Units for Recruitment of Fish (SMURFs) (Carr unpubl. data) from 3 established monitoring sites proximal to 2 marine protected areas, one at Anacapa
Island (Fig. 2A), and the other at Big Fisherman's Cove, Santa Catalina Island (Fig. 2B). Of these, 2 sites, 1 each at Hazards and Pelican Bays of Santa Cruz Island (SCZI) are maintained by researchers of the University of California, Santa Barbara, and lie (respectively) approximately 40 and $25 \mathrm{~km}$ (Fig. 2A), west of the MPA at Anacapa Island, a $24 \mathrm{yr}$ old no-take area of only $0.1 \mathrm{~km}^{2}$ along the extreme northeastern shore of Anacapa Island (Fig. 2A). Subtidal circulation is usually cyclonic around the central part of the Santa Barbara Channel, where an equatorward (easterly) flow runs along the Channel Islands, and a poleward (westerly) flow along the north (mainland) shore of the channel (Hendershott \& Winant 1996, Harms \& Winant 1998). Also, small cyclonic eddies frequently form near the center of the channel and then propagate westward at a rate of several kilometers per day (Harms \& Winant 1998). Thus, whereas the SCZI sites would be generally upwind of the MPA in summer, cyclonic circulation could probably bring planktonic larvae and juveniles to Hazards and Pelican Bays from Anacapa's
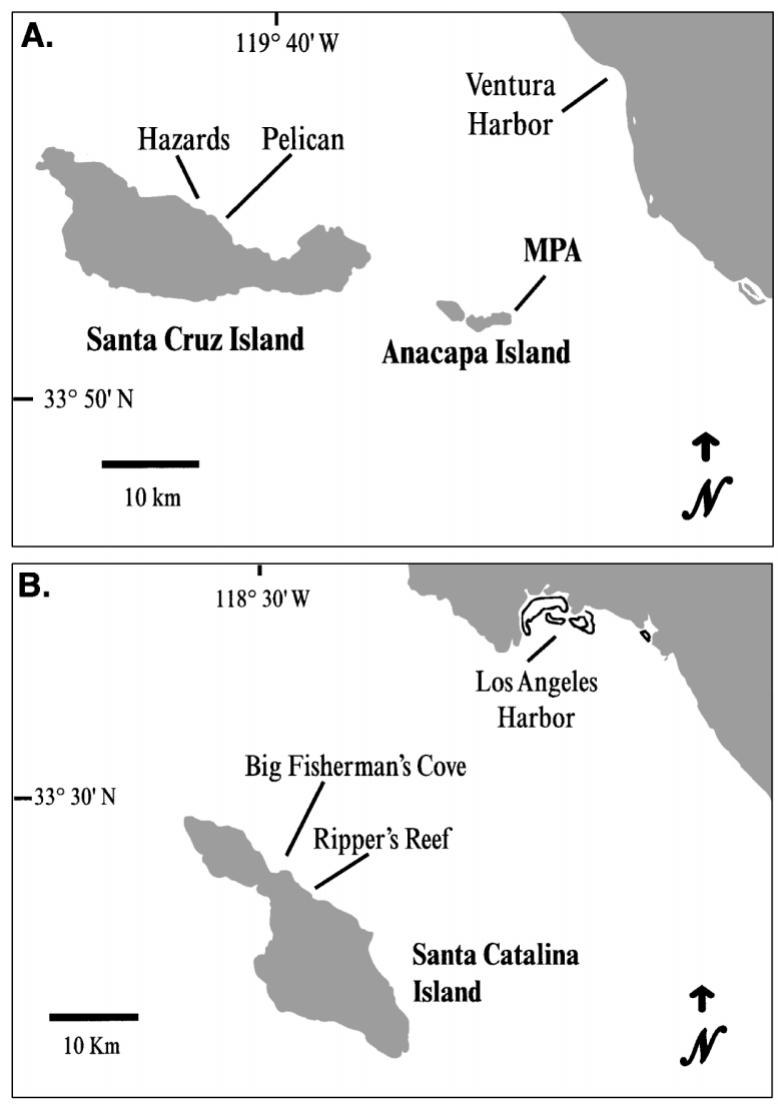

Fig. 2. Locations of Standard Monitoring Unit for Recruitment of Fish (SMURF) sites relative to nearest marine protected areas (MPA) off southern California. (A) Hazards and Pelican Bays on Santa Cruz Island, and the Anacapa MPA; (B) Ripper's Reef and the MPA at Big Fisherman's Cove, Santa Catalina Island 
MPA. The SCZI SMURFs were serviced at ca. 2 wk intervals. Juveniles were collected from 3 to 17 August, 2000 at Hazards $\left(\mathrm{N}_{1}=45\right)$ and Pelican $\left(\mathrm{N}_{2}=39\right)$ Bays. The juveniles were preserved in $70 \%$ ethanol and stored in glass vials at $4^{\circ} \mathrm{C}$ until use.

A third established site was Ripper's Reef (Findley \& Allen 2002) at Santa Catalina Island (SCAI). The site is ca. $5 \mathrm{~km}$ from the MPA in Big Fisherman's Cove (Fig. 2B), a 14 yr old, no-take reserve of $0.13 \mathrm{~km}^{2}$ lying along the northwestern face of SCAI. The physical areas of the reserve have been recently well characterized (Lowe et al. 2003). Ripper's Reef is generally upcurrent of Big Fisherman's Cove during flood tide and downcurrent during ebb tide (Zimmerman \& Kremer 1984). SMURFs sampled daily between 6 and 8 September 1998 (Findlay \& Allen 2002) comprised the sample $\left(\mathrm{N}_{3}=\right.$ 39). The juveniles were preserved in $80 \%$ ethanol and stored in glass vials at $4^{\circ} \mathrm{C}$. Finally, we obtained a sample of adult Paralabrax clathratus in October 2001 at an arbitrary site along the southeastern face of SCAI $\left(\mathrm{N}_{3}=\right.$ 39). A small fin clip was taken from each adult, preserved in $80 \%$ ethanol, and stored at $4{ }^{\circ} \mathrm{C}$.

The juveniles analyzed from SCZI were subsets of the SMURF collections. Continuous sampling for $2 \mathrm{wk}$ yielded fish over a range of lengths, suggesting a mixture of individuals that had recruited on different days. We required a sample of fish likely to have recruited on, or near, the same day, and thus our SCZI samples from Hazards Bay comprised 45 fish between 18.2 and $20.2 \mathrm{~mm}$ length, and those from Pelican Bay 39 fish between 9.1 and $11.7 \mathrm{~mm}$ length. The juveniles from SCAI were pooled from 3 consecutive-day collections to form a sample of 39 fish (Fig. 3) between 8.2 and $11.1 \mathrm{~mm}$ in length.

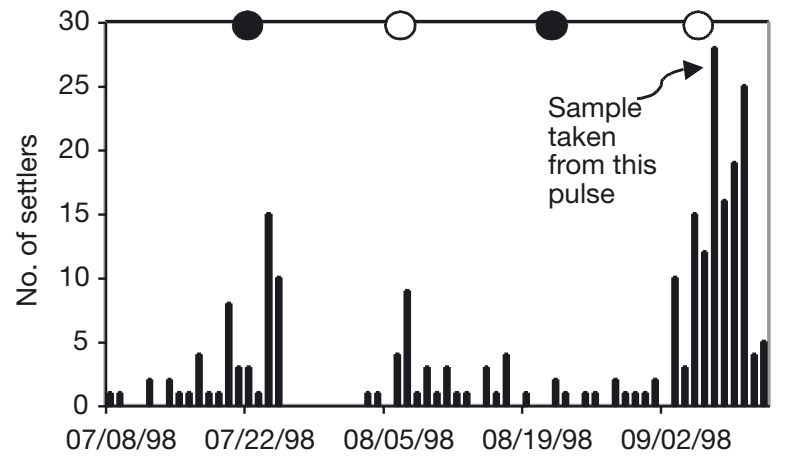

Fig. 3. Paralabrax clathratus. Daily settlement over $72 \mathrm{~d}$ (July-September 1998) at Ripper's Reef (Findlay \& Allen 2002) (dates given as mo/d/yr). (†) new moons; (O) full moons. Ripper's Reef sample $\left(\mathrm{N}_{3}=39\right)$ comprised 5 fish collected on 6 September, all 28 fish collected on 7 September, and 6 fish collected on 8 September. Standard length of juveniles was between 8.2 and $11.1 \mathrm{~mm}$. Modified from Fig. 3 of Findlay \& Allen (2002); used with permission of the publisher and authors
DNA extraction, PCR and sequencing. Whole genomic DNA was extracted from each juvenile using the QIAamp Tissue Kit, Qiagen \#29306 with 25 mg of tissue. The polymerase chain reaction (PCR) was performed in $100 \mu \mathrm{l}$ reactions using 95-98 $\mu \mathrm{l}$ master mix (see below) and 2-5 $\mu$ template DNA. The PCR primers were 12SARH as the reverse primer and CB3RL (Martin et al. 1992) as the forward primer. These primers amplified a target sequence of ca. $1300 \mathrm{bp}$ that included the control region of about $900 \mathrm{bp}$. The PCR master mix consisted of $10 \% 10 \times$ PCR buffer, $0.77 \% 100 \mathrm{mM}$ dNTPs, $0.74 \% 270 \mathrm{mM} 12 \mathrm{SARH}$ and CB3RL primers, $1 \%$ Nonidet $^{\circledR}-\mathrm{P} 40,1.9 \% 25 \mathrm{mM}$ $\mathrm{MgCl}_{2}, 82.5 \%$ distilled $\mathrm{H}_{2} \mathrm{O}$, and $0.4 \%$ (2 Units) AmpliTaq (Perkin-Elmer) DNA polymerase. We used the Perkin-Elmer 9600 gene amp system as follows: $92^{\circ} \mathrm{C}$ for $5 \mathrm{~min}$, then $92^{\circ} \mathrm{C}$ at $50 \mathrm{~s}, 54^{\circ} \mathrm{C}$ at $40 \mathrm{~s}$ and $70^{\circ} \mathrm{C}$ at $1.5 \mathrm{~min}$ for 34 cycles. Amplicons were gel-purified for sequencing on a $0.6 \%$ tris-acetate-EDTA (TAE) agarose gel, or purified using Millipore's Ultrafree-MC filtration units. Purified amplicons were cyclesequenced bidirectionally in a single reaction by the Sanger method (Sanger et al. 1977) with an Amersham kit (\#RPN2438) for primer-labeled sequencing. Forward- and reverse-sequencing primers were, respectively, 5'-AGTAGCTCAGCACCCAGAG-3' and 5'CAGCGTCAATGAAAGTGTGG-3'. The forwardsequencing primer lay outside our GenBank reference sequences (AF333426 and AF333427) by about 50 bases toward the transfer RNA (tRNA) Pro gene. The reverse-sequencing primer was between Bases 475 and 455 on the above-referenced sequences. Cycling parameters were $92^{\circ} \mathrm{C}$ at $2 \mathrm{~min}$, then $92^{\circ} \mathrm{C}$ at $30 \mathrm{~s}$, $52.2^{\circ} \mathrm{C}$ at $40 \mathrm{~s}$, and $70^{\circ} \mathrm{C}$ at $15 \mathrm{~s}$ for 31 cycles. The reaction was then run on a $0.2 \mathrm{~mm}$ tris-borate EDTA-polyacrylamide gel and sequenced using a LiCOR 4200-L2 autosequencer. We produced a contiguous sequence for each sample in SEQMAN (DNA*) from the forward and reverse sequences, and aligned these using MegAlign ( $\mathrm{DNA}^{*}$ ); haplotypes were defined by differences in 1 or more substitutions in pairwise comparisons. Shared haplotypes occurred in more than 1 fish; singletons were unique in the sample. The singleton fraction was expressed as the percentage of haplotypes found.

Data analyses. In our qualitative analyses we compared the singleton fraction of our adult Paralabrax clathratus from SCAI against the composite adult regression (Fig. 1); we also compared unpublished mtDNA data from 69 P. clathratus collected over a much greater geographic range of sampling (C. M. Phalen unpubl. data) to the composite. We tested for significant differences between our adult and each juvenile singleton count separately in $2 \times 2$ contingency tables using the $\chi^{2}$-test for homogeneity, plot- 
ting each juvenile value on the adult composite regression, and noting each observed singleton count relative to the $95 \%$ prediction intervals (Fig. 1). For $\chi^{2}$ analyses, we separated haplotypes into singleton and non-singleton, and the samples into adults and juveniles, where the threshold of significance $(\alpha=0.05)$ was near a $60 \%$ lower singleton count in the juvenile compared to the adult haplotype samples. In a slightly less stringent test we also compared singleton counts between juveniles and adults to the $\mathrm{N}$ of each sample of fish.

Analysis of the $\chi^{2}$-test suggested only incremental improvement in statistical power with sample sizes $>40$ individuals, and sample sizes near that number were available to us from the SMURFS. Even so, that number of individuals probably represents a marginally adequate sample (per site) for our study. However, the difficulty of servicing moored SMURFs at remote sites along the weather side of the northern Channel Islands can significantly hinder operations, making the successful collections valuable and worthy of study. We also used REAP (restriction enzyme analysis package) (McElroy et al. 1992) to perform a $\chi^{2}$-test of individual haplotype frequencies among populations using the Monte-Carlo method (Roff \& Bentzen 1989).

In our quantitative analyses we used Arlequin Software (Schneider et al. 2000) to perform AMOVA (analysis of molecular variance) (Excoffier et al. 1992) and mismatch distributions (Li 1977, Harpending 1994, Rogers 1995). We used AMOVA to estimate Wright's (Wright 1951, 1965, Weir \& Cockerham 1984) fixation index, $F_{\mathrm{ST}}$. A significant $F_{\mathrm{ST}}$ suggests that populations are not mixing considerably. Arlequin's mismatch distribution calculated frequency histograms of the number of observed versus expected substitutions (assuming recent population expansion as expected) between random pairwise comparisons of sequences. The distribution was useful in our study, because the number of modes appearing in the histogram reflects the genetic homogeneity of the sample (Rogers \& Harpending 1992).

We also estimated the genetic effective size, $N_{e}$ of each population using MIGRATE documentation and program (P. Beerli unpubl. data, available at http: \\ evolution.genetics.washington.edu/lamarc). MIGRATE uses a maximum-likelihood approach that considers the history of mutations and the uncertainty of the mtDNA genealogy (Beerli \& Felsenstein 1999) to estimate $\Theta$, where for bi-parental inheritance of a diploid marker $\Theta=4 \mathrm{~N}_{\mathrm{e}} \mu$, where $\mu$ is the mutation (i.e. substitution) rate. For the maternally inherited mtDNA we can determine only the female effective size $\mathrm{N}_{\text {ef, }}$, where $\Theta=2 \mathrm{~N}_{\text {ef }} \mu$ (e.g. Roman \& Palumbi 2003). The substitution rate, $\mu$, of the mtDNA control region of fishes is estimable from divergence rates over the whole control region at between 1.57 and $2.03 \times 10^{-8} \mathrm{bp}^{-1} \mathrm{yr}^{-1}$ (Donaldson \& Wilson 1999). However, in calculating $N_{\text {ef, }} \mu$ should be expressed per generation. If we arbitrarily assume that $10 \mathrm{yr}$ represent the average generation time of kelp bass populations with $100 \%$ maturation between 3 and 4 yr and life spans near 33 yr (Love 1996), then $\mu$ would fall between about 1.6 and $2.0 \times$ $10^{-7} \mathrm{bp}^{-1}$ generation ${ }^{-1}$. Taking the mid-point as $1.8 \times$ $10^{-7} \mathrm{bp}^{-1}$ generation $^{-1}$, then for each population sample $\mathrm{N}_{\text {ef }}=\Theta / 2 \mu=\Theta / 3.6 \times 10^{-7}$.

$\mathrm{N}_{\mathrm{e}}$ from the coalescent estimates the historical $\mathrm{N}_{\mathrm{e}}$ over the time period tracking back to the common ancestry of the alleles in the population (Avise 2000), rather than estimating the $\mathrm{N}_{\mathrm{e}}$ of the contemporaneous population. However, historical and contemporaneous estimates of $\mathrm{N}_{\mathrm{e}}$ can agree if population effective size has remained stable over a long period (e.g. Frankham et al. 2002, Turner et al. 2002). Whereas our central issue was indeed the number of females likely to have contributed to the contemporaneous genetic make-up of the recruiting juveniles, we were chiefly concerned with making a fair distinction between evidence of a small number of contributors (perhaps even as few as 100 female fish of a small MPA) and the tens to hundreds of thousands that might make up that effective size outside the MPA.

\section{RESULTS}

By combining all 4 population samples, we obtained 162 mtDNA sequences of 423 bases from the left domain of the kelp bass mtDNA control region. The 45 juveniles from Hazards Bay produced 19 distinct haplotypes, of which 12 were singletons, yielding a singleton fraction of $63 \%$. The 39 juveniles from Pelican Bay produced 24 distinct haplotypes, of which 19 were singletons, yielding a singleton fraction of $79 \%$. The 39 juveniles from Ripper's Reef produced 22 distinct haplotypes, of which 17 were singletons, yielding a singleton fraction of $77 \%$. Finally, the 39 adults from SCAI produced 24 distinct haplotypes of which 20 were singletons, yielding a singleton fraction of $83 \%$.

Collectively, the 4 samples had 37 nucleotide differences, generating 61 distinct haplotypes with 39 (64\%) singletons. Pooling of the juvenile samples alone produced 47 distinct haplotypes, of which 27 were singletons $(57 \%)$.

\section{Comparison of singleton fractions and $\chi^{2}$ tests}

The mtDNA singleton counts of our 39 adult kelp bass from SCAI closely agreed with that predicted from the composite adult regression, the value falling 


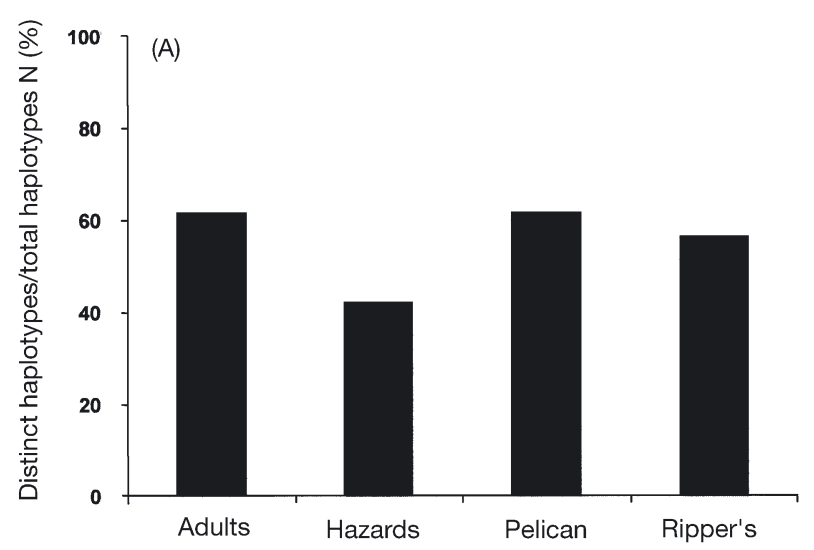

Table 1. Paralabrax clathratus. Distribution of haplotypes among the 4 population samples. REAP analysis for frequency heterogeneity was significant $(p<0.05)$

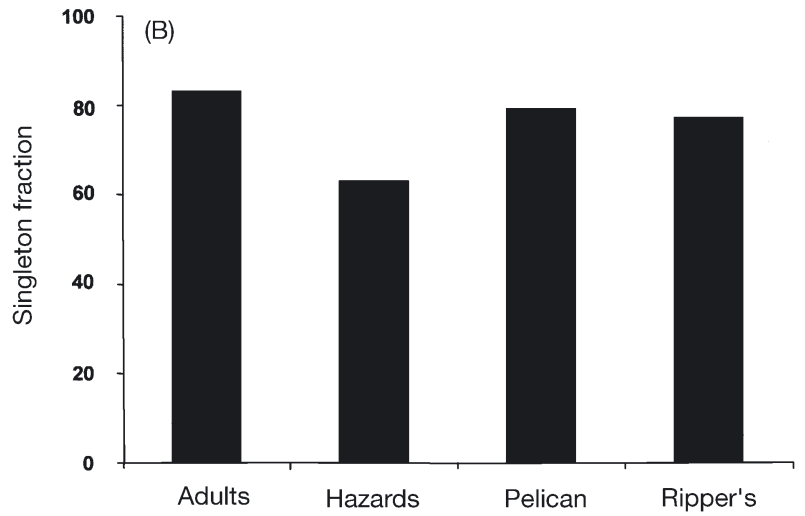

Fig. 4. Paralabrax clathratus. (A) Numbers of distinct haplotypes versus the total haplotypes in 3 juvenile and adult samples (i.e. the $\mathrm{N}$ sample); (B) numbers of singletons versus distinct haplotypes (singleton fraction) in juveniles and adults ( $p>0.05$ for each: separate $\chi^{2}$ tests)

well within the $95 \%$ prediction intervals of the regression line (Fig. 1), as was also true for each of our juvenile samples when compared separately. For example, $95 \%$ of singleton counts corresponding to a distinct haplotype count of 19, i.e. the Hazards Bay juvenile value, should fall between 6 and 21; the Hazards Bay singleton count was 12 . This was also true for a singleton count we derived from C. M. Phalen's (unpubl. data) sequence haplotype data for 69 kelp bass distributed between Baja California and the northern channel islands of California (data not shown). In contrast, the lumped juvenile singleton count was significantly lower than predicted. The $95 \%$ (inclusive) prediction for singletons at 47 haplotypes was 34 to 49 , whereas the observed count was 27 . The value was also below the $99 \%$ (inclusive) prediction range of 31 to 53 . The $\chi^{2}$-test of heterogeneity indicated that the singleton count for each juvenile sample relative to adult kelp bass was not significantly different (Fig. 4), thus agreeing with the regression analysis for individual samples.

\begin{tabular}{|c|c|c|c|c|}
\hline Haplotype & Hazards & Pelican & Ripper's & $\begin{array}{c}\text { Catalina } \\
\text { adults }\end{array}$ \\
\hline 1 & 18 & 10 & 12 & 6 \\
\hline 2 & 4 & 2 & 1 & 4 \\
\hline 3 & 2 & 0 & 0 & 0 \\
\hline 4 & 1 & 0 & 0 & 0 \\
\hline 5 & 2 & 0 & 2 & 0 \\
\hline 6 & 1 & 0 & 0 & 0 \\
\hline 7 & 1 & 1 & 0 & 0 \\
\hline 8 & 1 & 0 & 1 & 0 \\
\hline 9 & 2 & 0 & 1 & 1 \\
\hline 10 & 1 & 0 & 0 & 0 \\
\hline 11 & 1 & 1 & 1 & 0 \\
\hline 12 & 1 & 0 & 0 & 0 \\
\hline 13 & 1 & 0 & 0 & 0 \\
\hline 14 & 1 & 0 & 0 & 0 \\
\hline 15 & 3 & 3 & 2 & 1 \\
\hline 16 & 1 & 1 & 1 & 1 \\
\hline 17 & 1 & 0 & 0 & 1 \\
\hline 18 & 1 & 0 & 0 & 0 \\
\hline 19 & 2 & 0 & 0 & 0 \\
\hline 20 & 0 & 1 & 0 & 0 \\
\hline 21 & 0 & 1 & 1 & 0 \\
\hline 22 & 0 & 1 & 0 & 0 \\
\hline 23 & 0 & 1 & 0 & 0 \\
\hline 24 & 0 & 1 & 1 & 0 \\
\hline 25 & 0 & 1 & 0 & 0 \\
\hline 26 & 0 & 1 & 0 & 0 \\
\hline 27 & 0 & 1 & 0 & 0 \\
\hline 28 & 0 & 3 & 0 & 0 \\
\hline 29 & 0 & 1 & 0 & 0 \\
\hline 30 & 0 & 1 & 0 & 0 \\
\hline 31 & 0 & 2 & 0 & 1 \\
\hline 32 & 0 & 1 & 1 & 0 \\
\hline 33 & 0 & 1 & 0 & 0 \\
\hline 34 & 0 & 1 & 0 & 0 \\
\hline 35 & 0 & 1 & 1 & 1 \\
\hline 36 & 0 & 1 & 0 & 0 \\
\hline 37 & 0 & 1 & 0 & 0 \\
\hline 38 & 0 & 0 & 1 & 1 \\
\hline 39 & 0 & 0 & 0 & 2 \\
\hline 40 & 0 & 0 & 0 & 1 \\
\hline 41 & 0 & 0 & 4 & 7 \\
\hline 42 & 0 & 0 & 0 & 1 \\
\hline 43 & 0 & 0 & 0 & 1 \\
\hline 44 & 0 & 0 & 0 & 1 \\
\hline 45 & 0 & 0 & 0 & 1 \\
\hline 46 & 0 & 0 & 0 & 1 \\
\hline 47 & 0 & 0 & 0 & 1 \\
\hline 48 & 0 & 0 & 0 & 1 \\
\hline 49 & 0 & 0 & 0 & 1 \\
\hline 50 & 0 & 0 & 0 & 1 \\
\hline 51 & 0 & 0 & 0 & 1 \\
\hline 52 & 0 & 0 & 0 & 1 \\
\hline 53 & 0 & 0 & 0 & 1 \\
\hline 54 & 0 & 0 & 1 & 0 \\
\hline 55 & 0 & 0 & 1 & 0 \\
\hline 56 & 0 & 0 & 1 & 0 \\
\hline 57 & 0 & 0 & 1 & 0 \\
\hline 58 & 0 & 0 & 2 & 0 \\
\hline 59 & 0 & 0 & 1 & 0 \\
\hline 60 & 0 & 0 & 1 & 0 \\
\hline 61 & 0 & 0 & 1 & 0 \\
\hline
\end{tabular}


Table 2. Paralabrax clathratus. Pairwise $F_{\mathrm{ST}}$ values from AMOVA. $\left({ }^{*}\right.$ : statistically significant at $\alpha=0.05$ after applying Bonferroni correction to 6 tests). Juvenile samples were from Hazards and Pelican Bays and Ripper's Reef. Overall $F_{\mathrm{ST}}$ of 0.02 was significant $(p<0.05)$

\begin{tabular}{|lccc|}
\hline & Hazards & Pelican & Ripper's \\
\hline Hazards & - & - & - \\
Pelican & 0.010 & - & - \\
Ripper's & 0.009 & 0.019 & - \\
Adults & $0.041^{*}$ & 0.034 & 0.008 \\
& & & \\
\hline
\end{tabular}

\section{Haplotype frequency analysis and AMOVA}

Analysis with REAP found significant heterogeneity with respect to individual haplotype frequencies when the 4 samples were compared (Table 1). Removing the adult sample left non-significant differences among the 3 juvenile samples. The same was true when only the Hazards Bay or the Pelican Bay samples were separately removed. However, removing the Ripper's Reef sample but leaving the adult plus the 2 SCZI samples produced highly significant differences in the REAP analysis $(\mathrm{p}<0.001)$.

Analysis of molecular variances (AMOVA) produced a significant $F_{\text {st }}$ of $0.02(\mathrm{p}=0.03)$ among the 4 samples together (Table 2); $98.8 \%$ of the variance was attributable to within-sample variability. The $F_{\mathrm{ST}}$ among the juvenile samples alone was not significant, in agreement with the REAP analysis. However, there was a significant $(p<0.05) F_{\text {ST }}$ between the Hazards Bay and adult SCAI samples, but not between the Pelican Bay and adult SCAI samples or between the Ripper's Reef and the adult SCAI samples (Table 2). The gene diversity index of the Hazards Bay sample was $0.828 \pm 0.052$ and the nucleotide diversity index was $0.004 \pm 0.003$. The same values for the Pelican Bay sample were 0.914 \pm 0.036 and $0.005 \pm 0.003$, respectively, for the Ripper's Reef sample $0.895 \pm 0.040$ and $0.005 \pm 0.003$, and for the adult SCAI sample $0.924 \pm 0.027$ and $0.005 \pm 0.003$.

\section{Mismatch distribution}

Of the samples, 3 (Hazards Bay and Ripper's Reef juveniles, and adult SCAI sample), had unimodal mismatch distributions (Fig. 5), none of which differed significantly from the expected distributions of pairwise differences for recently-expanded populations. The Pelican Bay sample did not converge to fit the mismatch model distributions; perhaps it deviated too far from the sudden expansion model used in the Arlequin calculation (Schneider et al. 2000). The mean pairwise difference among the haplotypes of the Hazards Bay juveniles was 1.71 with the variance term $s^{2}=1.50$, among the Pelican Bay haplotypes it was 2.24, with $s^{2}=1.82$; and among the Ripper's Reef haplotypes it was 2.30 , with $s^{2}=$ 2.14 , respectively. The observed mean and variance for the adult SCAI haplotypes was 2.31 , with $s^{2}=1.83$.

\section{Effective population size}

We estimated the female effective population size, $\mathrm{N}_{\text {ef }}$, using the expression $\mathrm{N}_{\text {ef }}=\Theta / 2 \mu$ as follows: Hazards Bay $\Theta=0.00211, \mathrm{~N}_{\text {ef }}=5861$; Pelican Bay, $\Theta=$ $0.01698, \mathrm{~N}_{\mathrm{ef}}=47167$; Ripper's Reef, $\Theta=0.01764, \mathrm{~N}_{\mathrm{ef}}=$ 49000 , SCAI adults $\Theta=0.02696, \mathrm{~N}_{\text {ef }}=74889$.

\section{DISCUSSION}

The singleton haplotype count for our adult Paralabrax clathratus fell on the composite regression line
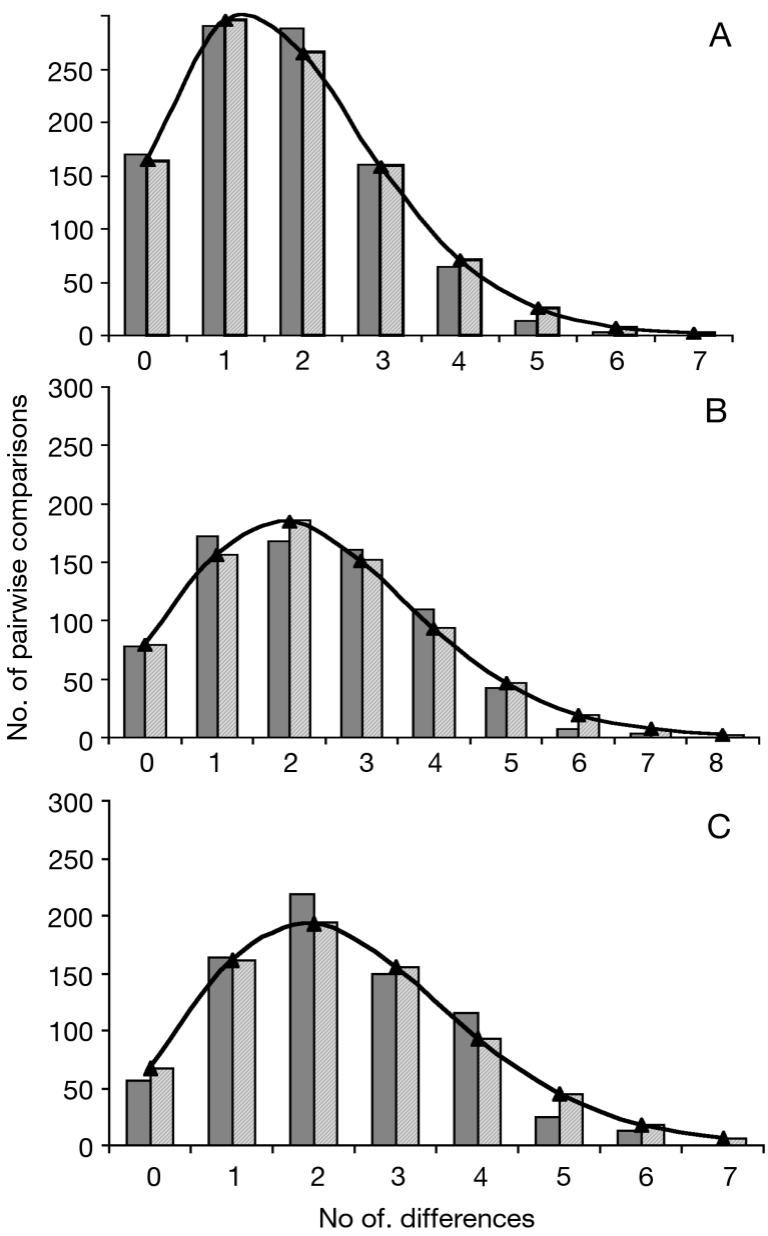

Fig. 5. Paralabrax clathratus. Mismatch histograms of (A) Hazards Bay; (B) Ripper's Reef, (C) Santa Catalina adults. Dark bars: observed frequency; light bars: simulated frequency 
constructed from data from other studies, and was well within the $95 \%$ prediction interval for new observations (Fig. 1). The same was true for C. M. Phalen's (unpubl. data) larger sample of 69 adults taken from 7 locations throughout the geographic range of kelp bass (data not shown). Consequently, our adult sample from an arbitrary location did not produce a biased reference singleton count. Haplotype and singleton counts for each of the 3 juvenile samples appeared slightly, but not significantly, lower than that for the SCAI adults (Fig. 4). Moreover, each juvenile sample, when plotted individually, fell directly on the composite adult regression line (Fig. 1). Thus, there was no evidence from the singleton counts that siblingdominated recruitment was occurring at any of the 3 individual sites when the juveniles were collected.

The linear distance separating the SCZI sites and Anacapa's tiny no-take MPA is not especially large (ca. 25 and $40 \mathrm{~km}$, respectively), but because juveniles arising from the MPA and recruiting to SCZI would not be 'homing', natal homing per se to an MPA would not be an issue there. Although cyclonic subtidal circulation in the Santa Barbara Channel (Hendershott \& Winant 1996, Harms \& Winant 1998) could conceivably supply the SCZI sites with recruits from Anacapa, a significantly enhanced recruitment effect might not extend over even that distance. Moreover, because the SCZI samples represented 2 wk integrations of recruits, one might expect genetically mixed recruitment. Relative to the SCZI sites, the Ripper's Reef site (Fig. 2B) was much nearer (about $5 \mathrm{~km}$ ) to a larger MPA at Big Fisherman's Cove, Santa Catalina Island (Fig. 2B). Ripper's lies upcurrent or downcurrent of the MPA, depending on the tide, but is generally leeward of it during summer and fall (Zimmerman \& Kremer 1984). Ripper's Reef juveniles were taken from peaks of daily recruitment that formed an apparent strong recruitment pulse coinciding with the full moon (Fig. 3 ); yet, the findings were essentially the same as those seen at the SCZI sites.

The traditional analyses yielded further insight. Qualitative and quantitative genetic differences did appear between the adult and some juvenile samples. In considering them, however, it should be recalled that the Ripper's Reef and SCZI juveniles were collected 2 yr apart, in 1998 and 2000, respectively, and that SCAI adults were collected in 2001. So, although intra-annual syntopic events could not account for any patterns seen, we shall discuss our findings as if the 'composite view' from multi-year sampling reflects what could be occurring in 1 representative year.

There was significant frequency heterogeneity among individual haplotypes between the SCZI juveniles and SCAI adults, even though the Ripper's Reef juveniles did not differ from those from SCZI. The pat- tern implies at least partial mixing between the southern and northern Channel Islands during planktonic dispersal. The significant $F_{\mathrm{ST}}$ between the Hazards Bay juveniles and SCAI adults revealed by AMOVA (Table 2) makes it unlikely that those adults contribute much recruitment to the northwestern shores of Santa Cruz Island. It is substantially more likely that the local adult kelp bass contributed recruitment to Santa Catalina Island, or that the source of recruits to Santa Catalina Island was the same for the juveniles and adults. The juveniles and adults shared 2 haplotypes that were altogether lacking among the SCZI juveniles (Table 1).

The average number of sites by which most sequence pairs differed within the Hazards Bay sample (1.7 sites) compared to the 2 individual SCAI samples (ca. 2.3 sites) makes the entire Catalina Island population appear slightly more diverse and consequently slightly older than the SCZI population (Rogers \& Harpending 1992). The slightly, if not significantly, higher adult singleton count coupled with the slightly higher gene diversity (even compared to the Ripper's Reef juveniles), for the Catalina Island population suggests that the adult sequences are more divergent than the juvenile ones. The adults had a slightly larger subset of the distinct mtDNA haplotypes of the kelp bass population at large than did the Ripper's Reef juveniles. This would be expected, as the juveniles represent only females spawning in a single year rather than a genetic assemblage from multiple recruitment years.

We estimated the female genetic effective size of the SCAI adult population to be about 1.5 to 1.6 times larger than that of the Ripper's Reef and Pelican Bay juveniles, respectively, but nearly 13 times that of the Hazards Bay juveniles. The estimates directly reflect the differing amounts of sequence divergences within and between samples; i.e. increasing nucleotide diversity within a sample of haplotypes generates proportionately higher values of $\mathrm{N}_{\text {ef }}$ by the coalescent. The magnitudes of $\mathrm{N}_{\mathrm{ef}}$ were set by the value of $\mu$ that we used (Donaldson \& Wilson 1999) and an assumed average generation time of $10 \mathrm{yr}$. Germane to the context of this research is (1) whether the estimates have led to erroneously high estimates of $\mathrm{N}_{\text {ef }}$, and (2) whether the coalescent method as we have applied it approximates the $\mathrm{N}_{\mathrm{ef}}$ of the contemporaneous population.

Regarding the first point, higher values of $\mu$ coupled with higher generation times lowers the estimates of

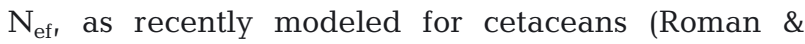
Palumbi 2003). Moving to an outside (average) upper estimate of $\mu$ for fish control regions of $2.03 \times 10^{-8} \mathrm{bp}^{-1}$ $\mathrm{yr}^{-1}$ and doubling the average generation time in kelp bass from 10 to 20 yr would put the $\mathrm{N}_{\text {ef }}$ of the Hazards Bay juveniles (already our lowest estimate) at 2598- 
not a particularly large number. Regarding the second point, the mismatch distribution for the Hazards Bay juveniles (Fig. 5) is consistent with the distribution expected following a relatively recent expansion in population size (Rogers \& Harpending 1992). If an historically stable population size is necessary for the coalescent approach to produce a fair approximation of the contemporaneous $\mathrm{N}_{\mathrm{ef}}$ (e.g. Frankham et al. 2002, Turner 2002), then this condition may not be met for kelp bass.

However, our estimated female effective sizes taken together with our singleton comparisons, haplotype frequency analysis, AMOVA, and mismatch distributions, revealed no compelling evidence of significantly enhanced recruitment above what would be regarded as 'background' near an MPA. Consequently, our findings offer almost no support for a basic model concept of a relatively few, highly productive females supporting a small MPA or its proximal areas, either by way of direct juvenile natal homing (Jones et al. 1999) or other retention mechanisms (Stepien 1999, Swearer et al. 1999). Still, so little is known of the planktonic dispersal patterns of kelp bass that there is no established basis for predicting the importance of retention or natal homing to recruitment success, or for knowing if such behavior exists for this species. If it does, it was not seen here, but given perhaps our marginal power of detection, its existence cannot be ruled out, nor can one conclude that no recruitment effects attributable to MPAs are occurring in our study areas, or that they will not be detected in association with MPAs elsewhere.

Regarding the observation that the singleton count of the pooled juvenile sample was significantly lower than predicted, we offer the following explanation. Because the pooled sample comprised juveniles collected in different years at different sites, the lowered count clearly would not be evidence of siblingdominated recruitment near a specific site. Fitting the result into the inter-annual composite view with our other findings, it likewise suggests that the recruiting juveniles were drawn from a genetically mixed pool, where at least nominal siblings (i.e. individuals sharing haplotypes but not necessarily true siblings) were relatively abundant. This pattern disappeared at recruitment because the nominal groups were basically not cohesive. Nevertheless, the lowered count confirms our premise that, in a finite field sample of recruiting juvenile kelp bass, our composite regression approach can recognize a significantly increased number of shared haplotypes over that typically seen among adult fishes.

Planktonic dispersal and recruitment among marine populations is recognized as difficult to study genetically (Hellberg et al. 2002). The geographic scales over which enhanced recruitment effects may exist and be attributable to either large or small MPAs are likewise difficult to study or predict, but much more research effort should be directed toward understanding scale. Knowledge of population sources, levels of mixing among populations, and the direction and scope of larval dispersal is imperative for preserving multiple life stages and stage-specific habitats. Seeking genetic evidence of sibling-dominated recruitment via mtDNA haplotype analysis represents 1 possible approach to the recruitment issues surrounding MPAs, especially when combined with traditional methods of analysis.

Acknowledgements. We thank A. M. Findlay and L. G. Allen for samples of Paralabrax clathratus juveniles from Ripper's Reef, Santa Catalina Island; J. E. Caselle for samples of P. clathratus juveniles from Hazards and Pelican Bays, Santa Cruz Island; the 'Vantuna' Research Group for collection of P. clathratus adults from Santa Catalina Island; and C. G. Lowe and J. W. Archie for thoughtful discussions that helped develop the original research. We also thank S. A. Karl, J. M. Leis, C. A. Stepien, and 2 anonymous reviewers for insightful comments and discussion that improved the manuscript. We acknowledge financial support from the College of Natural Sciences and Mathematics, CSU Long Beach, and the Marine Biology Education Foundation of the Southern California Tuna Club.

\section{LITERATURE CITED}

Avise JC (2000) Phylogeography: the history and formation of species. Harvard University Press, Cambridge, MA

Beerli P, Felsenstein J (1999) Maximum-likelihood estimation of migration rates and population numbers of 2 populations using a coalescent approach. Genetics 152:763-773

Bowen BW, Grant WS (1997) Phylogeography of the sardines (Sardinops spp.): assessing biogeographic models and population histories in temperate upwelling zones. Evolution 51:1601-1610

Brown JR, Beckenbach AT, Smith MJ (1993) Intraspecific DNA sequence variation of the mitochondrial control region of white sturgeon (Acipenser transmontanus). Mol Biol Evol 10:326-341

Chiappone M, Sullivan Sealey KM (2000) Marine reserve design criteria and measures of success: lessons learned from the Exuma Cays Land and Sea Park, Bahamas. Bull Mar Sci 66:691-705

Conover DO, Travis J, Coleman FC (2000) Essential fish habitat and marine reserves: an introduction to the second Mote Symposium in fisheries ecology. Bull Mar Sci 66: 527-534

Cordes JF, Allen LG (1997) Estimates of age, growth, and settlement from otoliths of young-of-the-year kelp bass (Paralabrax clathratus). Bull Southn Calif Acad Sci 96:43-60

Dawson MN, Staton, JL, Jacobs DK (2002) Comparative phylogeography of sympatric sister species, Clevelandia ios and Eucyclogobius newberryi (Teleostei, Gobiidae), across the California Transition Zone. Mol Ecol 11: 1065-1075

Donaldson KA, Wilson Jr RR (1999) Amphi-Panamic geminates of snook (Percoidei: Centropomidae) provide a calibration of the divergence rate in the mitochondrial DNA control region of fishes. Mol Phylogenet Evol 13:208-213 Excoffier L, Smouse PE, Quattro JM (1992) Analysis of molec- 
ular variance inferred from metric distances among DNA haplotypes: applications to human mitochondrial DNA restriction data. Genetics 131:479-491

Findlay AM, Allen LG (2002) Temporal patterns of settlement in the temperate reef fish, Paralabrax clathratus. Mar Ecol Prog Ser 238:237-248

Frankham R, Ballou JD, Briscoe DA (2002) Introduction to conservation genetics, Cambridge University Press, Cambridge

Harms S, Winant CD (1998) Characteristic patterns of circulation in the Santa Barbara Channel. J Geophys Res C 103: 3041-3065

Harpending RC (1994) Signature of ancient population growth in a low-resolution mitochondrial DNA mismatch distribution. Hum Biol 66:591-600

Hellberg ME, Burton RS, Neigel JE, Palumbi SR (2002) Genetic assessment of connectivity among marine populations. Bull Mar Sci 70:273-290

Hendershott MC, Winant CD (1996) The circulation in the Santa Barbara Channel, Oceanography 9:114-121

Jones GP, Millcich MJ, Emslie MJ, Lunow C (1999) Selfrecruitment in a coral reef fish population. Nature 402: 802-804

Li WH (1977) Distribution of nucleotide differences between 2 randomly chosen cistrons in a finite population. Genetics 85:331-337

Love M (1996) Probably more than you want to know about the fishes of the Pacific Coast, Santa Barbara. Really Big Press, Santa Barbara, CA

Lowe CG, Topping DT, Cartamil DP, Papastamatiou YP (2003) Movement patterns, home range, and habitat utilization of adult kelp bass, Paralabrax clathratus in a temperate, notake marine reserve. Mar Ecol Prog Ser 256:205-216

Martin AP, Humphreys R, Palumbi SR (1992) Population genetic structure of the armorhead, Pseudopentaceros wheeleri, in the North Pacific Ocean: applications of the polymerase chain reaction to fisheries problems. Can J Fish Aquat Sci 49:2386-2391

McElroy D, Moran P, Bermingham E, Kornfield I (1992) REAP an integrated environment for the manipulation and phylogenetic analysis of restriction data. J Hered 83:157-158

Roberts CM, Bohnsack JA, Gell F, Hawkins JP, Goodridge R (2001) Effects of marine reserves on adjacent fisheries. Science 294:1920-1923

Roff DA, Bentzen P (1989) The statistical analysis of mitochondrial DNA polymorphisms: $\chi^{2}$ and the problem of small samples. Mol Biol Evol 6:539-545

Rogers A (1995) Genetic evidence for a Pleistocene population explosion. Evolution 49:608-615

Rogers AR, Harpending H (1992) Population growth makes waves in the distribution of pairwise genetic distances. Mol Biol Evol 9:552-569

Roman J, Palumbi SR (2003) Whales before whaling in the North Atlantic. Science 301:508-510

Sanger F, Milkin S, Coulson AR (1977) DNA sequencing with chain-terminating inhibitors. Proc Natl Acad Sci USA 74: $5463-5467$

Schneider S, Roessli D, Excoffier L (2000) Arlequin: a software

Editorial responsibility: Otto Kinne (Editor),

Oldendorf/Luhe, Germany for population genetics data analysis, Version 2.000, Genetics and Biometry Laboratory, Department of Anthropology, University of Geneva

Shields GF, Gust JR (1995) Lack of geographic structure in mitochondrial DNA sequences of Bering Sea walleye pollack, Theragra chalcogramma. Mol Mar Biol Biotechnol 4: 69-82

Stepien CA (1995) Population genetic divergence and geographic patterns from DNA sequences: examples from marine and freshwater fishes. In: Nielsen JL (ed) Evolution and aquatic ecosystems: defining unique units in population conservation. Trans Am Fish Soc Symp 17. American Fisheries Society, Bethesda, MD, p 263-287

Stepien CA (1999) Phylogeographic structure of the Dover sole Microstomus pacificus: the larval retention hypothesis and genetic divergence along the deep continental slope of the northeastern Pacific Ocean. Mol Ecol 8:923-939

Stepien CA, Faber JE (1998) Population genetic structure, phylogeography, and spawning philopatry in walleye (Stizostedion vitreum) from mtDNA control region sequences. Mol Ecol 7:1757-1769

Stepien CA, Dillon AK, Patterson AK (2000) Population genetics, phylogeography, and systematics of the thornyhead rockfishes (Sebastolobus) along the deep continental slopes of the North Pacific Ocean. Can J Fish Aquat Sci 57: 1701-1717

Swearer SE, Caselle JE, Lea DW, Warner RR (1999) Larval retention and recruitment in an island population of a coral-reef fish. Nature 402:799-802

Turner TF, Wares JP, Gold JR (2002) Genetic effective size is three orders of magnitude smaller than adult census size in an abundant, estuarine-dependent marine fish (SCiaenops ocellatus). Genetics 162:1329-1339

Victor BC (1987) Duration of the planktonic larval of one hundred species of Pacific and Atlantic wrasses (family Labridae). Mar Biol 90:317-326

Waples RS (1987) A multispecies approach to the analysis of gene flow in marine shore fishes. Evolution 41:385-400

Weir BS, Cockerham CC (1984) Estimating F-statistics for the analysis of population structure. Evolution 38:1358-1370

Wilson Jr RR, Donaldson KA (1998) Restriction digest of PCRamplified mtDNA from fin clips is an assay for sequence genetic 'tags' among hundreds of fish in wild populations. Mol Mar Biol Biotechnol 7:39-47

Wilson Jr RR, Donaldson KA, Frischer ME, Young TB (1997) Mitochondrial DNA control region of common snook and its proposed use as a genetic tag. Trans Am Fish Soc 126: $594-606$

Wright S (1951) The genetical structure of populations. Ann Eugen 15:323-354

Wright S (1965) The interpretation of population structure by $F$-statistics with special regard to systems of mating. Evolution 19:395-420

Young P (1963) The kelp bass (Paralabrax clathratus) and its fishery, 1947-1958. Calif Dep Fish Game Fish Bull 122:67

Zimmerman RC, Kremer JN (1984) Episodic nutrient supply to a kelp forest ecosystem in southern California. J Mar Res 42:591-604

Submitted: June 2, 2003; Accepted: April 6, 2004

Proofs received from author(s): August 2, 2004 